\title{
Mental Space Theory on Presupposition Projections in Advertisements
}

\author{
Ling Guo ${ }^{1}$ \\ 1 School of Foreign Languages, Shanghai University, Shanghai, China \\ Correspondence: Ling Guo, School of Foreign Languages, Shanghai University, Shanghai, China.
}

Received: July 20, 2020

doi:10.5430/irhe.v5n3p84
Accepted: September 6, $2020 \quad$ Online Published: November 10, 2020

URL: https://doi.org/10.5430/irhe.v5n3p84

\begin{abstract}
In this economic society in which information is prevailing, advertisements are found here and there, and play a very important role in our daily life. More and more importance is attached to the research of advertising language. This paper reveals presupposition projection problems in advertising, especially in English advertising. It aims to explore the explanation of mental space theory for cancellation or inheritability of presupposition in advertising, that is, the projection problem of presupposition. Different from how traditional presupposition theory is used in seeking for a reasonable explanation for projection problems, this paper will investigate in detail projection problems in advancing from the perspective of Fauconnier's mental space theory in combination with large quantities of advertisement examples.
\end{abstract}

Keywords: mental space, advertising, presupposition, projection

\section{Introduction}

In the present information age, our world is inundated with advertisements, which mirror and shape our lives, culture and society. With the increasing part played by advertisements, people are beginning to make much of the language of advertising. Under this circumstance, great important has been attached to the quantitative or qualitative study of the lexical, syntactical, grammatical and rhetorical features of advertisements. Various scholars have in recent years contributed to the study of projection of presupposition by analyzing its sematic and pragmatic rules in texts (e.g. Heim, Gazdar, Karttunen, Peters \& Stalnaker). The use of projection as an analytical tool can provide a number of insights into how meaning is constructed in texts. Although scholars tend to have various views on how to explain the projection phenomenon when studying a text, the fact is that projection rules are not expected to function in the same way in various discourse backgrounds. Therefore, the theoretical value of this paper is to explain presupposition projection from the perspective of mental space theory across two languages: English and Chinese, especially within the context of advertising texts.

\subsection{Research Background}

The theory of presupposition was first put forward bu a German philosopher Frege in 1892. Afterwards, presupposition was extensively applied to other syntactic structures by Morgan, Chomsky and Karttunen, etc. and to lexical items by Horn, Kiparsky, Fillmore and Karttunen in 1960s and 1970s. For example, Karttunen elaborated on presupposition in his "presuppositions of compound sentences" (1973) and "Conventional Implicature" (1979). Before 1970s, the concept of presupposition was largely restricted to the domain of truth-conditional semantics. However, with the increasing prominence of pragmatics during the 1970s, the above position was challenged. The notion of pragmatic presupposition was introduced by Stalnaker (1970) as one of the major factors of context and was further developed by Fillmore, Karttunen, Gazdar, McCawley, Lenvinson, Van Der Sandt, Lambrecht and others. For several years, debate on whether presupposition is a semantic issue or pragmatic issue has been on the increase. But after several years' experimental studies and research, researchers tend to regard presupposition as a phenomenon of pragmatic conception, since its existence contributes primarily to the context and the knowledge about the world we live in.

\subsection{Objective}

Then what is the objective of this study? At the very beginning, it is mentioned that various scholars have in recent years contributed to the study of projection of presupposition by analyzing its semantic and pragmatic rules in texts. However, how to explain projection problems from a more comprehensive way remains unsolved. As for the language of English advertising per se, the description and explanation of presupposition projection are somewhat 
inadequate and insufficient.

Therefore, on the basis of previous researches, this paper is intended to explain presupposition projection problems in advertisements in virtue of mental space theory. And the purpose of this paper is to try to explore how the combination of mental space theory and presupposition projection helps to achieve the persuasive power of advertising language. Efforts will be made to obtain some insightful views of the pragmatic functions of presupposition in English advertising. Starting from both the advertisers' view and from the consumers' stand, the practical application value of this paper is to read and comprehend advertisements with a new guiding direction, that is, to relate several mental spaces together to generate the very subject that the advertisers are genuinely targetting at and also to attract more and more consumers to purchase what the advertisers are promoting in a more effective and feasible way.

\section{Theoretical Background}

\subsection{Brief Review of the Study on Presupposition}

Presupposition originates with debates in philosophy, specifically with debates about the nature of reference and referring expressions. It is now a subject widely studied and applied. The German philosopher and logician Frege has an account for presupposition. "If anything is asserted, there is always an obvious presupposition that the simple or compound proer names have a reference" (Levinson, 2001). For instance, if one asserts that "Kepler has a son", this expression presupposes that "there is a person called Kepler existing"; otherwise, the assertion is meaningless.

Then at the beginning of last century, English philosopher Russell proposed another approach to presupposition. Struggling with the same problems concerned with reference, he came to quite different conclusions. He put forward the two-value logic that is distinct from that of Frege. He assumed that a sentence has two possible truth-value relations to the given situation - it can be true or can be false. Russell held that if one of the presuppositions in conjunctions of propositions is false, then the whole sentence with conjunctions of propositions is false. According to him, the following example corresponds to conjunctions of propositions.

[1] The Emperor of China is mounting Mountain Tai.

[2] There exists a present Emperor of China.

The presupposition is false because there is no emperor in China today since China is now a Socialism nation. Russell's view remained unchallenged until Strawson proposed a different approach. Starting from Russell's analysis, Strawson gave a 3-value logic. In his view, there is a third possibility to the proposition in addition to "true" and "false". Supposing that someone else said to you, "The Emperor of China is mounting Mountain Tai", and asked you whether you thought what he said was true or false. Then you would say that the question he asked in fact did not arise, because there was no much a person as the emperor of China today. Starwson also suggested that whether such a statement is true of false actually depends on the language users. Or we can say it depends on the relations between all elements and components of the propositions. What's more important, Strawson enlarged the scope of presupposition phenomena. Apart from definte descriptions, proper names and qualification noun phrases, some other parts of an utterance, like temporal clause and change-of-stage words can also trigger a presupposition. Since Strawson's work, the discussion on presupposition has been connected with context, which, in turn, is related to pragmatics. This was also the turning point for presupposition from semantic study to pragmatic study.

\subsection{Mental Space Theory}

Mental space theory, originally proposed by Gilles Fauconnier (1985) to describe how language users assign and manipulate reference, including the use of names, definte description, and pronouns. It is general knowledge that mental space theory belongs to the scope of cognitive field. However, with the integration and overlapping use of cognitive science and other disciplines, mental space theory, as one branch of cognitive field, has also been widely and universally applied in mathematics, music, kinestics, etc. But in this paper, it is combined with presupposition in pragmatics together to illustrate projection phenomenon in advertising.

\section{Application of Presupposition in Advertising}

\subsection{Advertising}

In this study, advertising, specifically printed advertising language will be referred to as referential materials for its theoretical application, which is most persuasive and pervasive in its power to attract more audience.

\subsection{Classification of Presupposition in Advertising}

Advertising language, as a kind of persuasive language, has to employ various strategies in order to convince the 
customers. It is no exaggeration to say that successful advertisements are based upon the systematic study of social psychology, especially the psychology of the consumers. Presupposition, highly related to psychology with a potentially powerful property, is the very strategy that advertisers apply in advertising. Due to this specific feature of advertising language, it seems to have the potential to convince hearers of the truth of a presupposition more effectively than assertions. What an advertiser is seeking for is to convince consumers to believe in what they have said, to buy their productions and to accept their service as their final target. This is exactly the reason why presuppositions have a very significant role to play in advertisements.

There are many different types of presuppositions or many different ways of presupposing. Semantically, presupposition has been associated with the use of a large number of words, phrases and structures. And presuppositions are, in most cases, produced by lexical items and syntactical constructions, which are called presupposition triggers. Therefore, two major types of presuppositions are recognized, that is, existential presupposition and factive presupposition.

\subsubsection{Existential Presupposition}

From the semantic perspective, presupposition presupposes the existence or presence of something or some ideas. That is, existential presupposition is indispensable in order for advertising to play its role. It is a basic kind of presupposition, which is usually triggered by definite descriptions which are formed by using proper names, definite article, demonstrative pronouns like "this, that, these, those" and possesives like "my, your, our" and so on.

According to the study of psychology, it has been common knowledge to all that human beings are willing to conduct easier things. For example, they prefer watching TV to reading a book; they prefer driving their own car to taking mass transit with the precondition that they have a car; they prefer looking up a word in a software dictionary in a computer to using a printed dictionary. Likewise, in order not to expend much more efforts to accomplish something, existential presupposition unavoidably comes into play in that it not only provides the premises for the reader to process, but also saves people a lot of efforts by means of combining several propositions into one short definite noun phrase.

Let us study the following example taken from an English advertisement and see how existential presupposition works in an appropriate and effective way.

\section{[3] An intimate party. The inhibited fragrance. (From Relvon)}

Short as this advertisement is, it can leave a deep imppression on the readers in that it adopts various language skills. Of course, here our concern will not be focused on the application of existential presupposition. The most obvious is the one triggered by the definite article "the", which presupposes that there exists something that has "inhibited fragnance". Besides, the proper name Relvon, a worldwide famous cosmetics brand, also generates an existential presupposition. An important function of presupposition here is to promote within advertisement an idea that "inhibited fragnance" is somehow related to perfume and party.

Here comes another example about instant full cream powder.

[4] This instant full cream powder is made from Premium A Grade milk... This milk powder gives you the same nutritional value as fresh milk because it contains vitamins A, B1, B2, B6, B12, C, D...

This piece of advertisement achieves a similar function in virtue of existential presupposition signaled by the definite article "the" and the demonstrative pronoun "this". Therefore, it presupposes the existence of instant full cream powder, Premium A Grade milk and the same nutritional value and also the close relations among these things.

Based on the above analysis, it is manifest that through a subtle use of existential presupposition, an advertisement will make good impressions on consumers, and thereby influence their attitudes and behaviors.

\subsubsection{Factive Presupposition}

Just ad the proverb goes, "Facts speak louder than words". In order to influence the attitudes and/or the behaviors of an individual or even a group of people, it is very necessary to present some facts to them. From the psychological point of view, their attitudes will be affected very subtly and will be geared towards the facts presented to them. Therefore, their action will perhaps be activated. Although sometimes consumers know well that the fact that an advertisement is persupposing is only assumed to be true, yet an advertisement writer can still try as he can to manipulate the presupposition process to work for his purposes. Why? Because it is self-evident that the way of presenting information through the use of presupposition is faily beneficial either to the advertising agency or to the producer or manufacturer, etc. Holding this in mind, the advertisers often present what seems to be facts to convince their target consumers. For example: 
[5] Why is it that so many people of distinction choose PARKER writing instruments over all others?

One eye on this sentence, almost every one would give the assertion that this is a question. Of course it is. However, putting this sentence in an advertising context will further give our readers another impression that, as a matter of fact, the advertiser is conveying factual information that many people of distinction have chosen PARKER writing instruments, but not others. That is, he or she is trying to persuade consumers to purchase PARKER writing instruments since other people of distinction are using them too. This way of factive presupposition exactly takes advantage of people's vanity in following others. However, people usually will not take much time and trouble to prove the truth of it. As it is, most consumers will accept such presupposed facts as true and will not bother to carry out any investigation. They usually take two options: either to take the purchase action or not.

\subsection{Functions of Presuppositions in Advertising Language}

Through description of features and functions of presupposition and advertising, we have noticed functions of presupposition in advertising. The presupposed characteristics of presupposition are propitious to the conciseness and interestingness of advertising. Just as presupposition's characteristics and the language of advertising share something in common, presuppositions as a very important notion in pragmatics can serve the multiple purposes in advertisement. As we can see, the functions presupposition has in the form of advertising language are comparatively more directly perceived through the senses. The influence of presupposition in the form of advertising language mainly exists in the following two broad aspects: presupposition and conciseness of advertising language and presupposition and art of advertising language.

\subsubsection{Presupposition and Conciseness of Advertising Language}

In this economic society, advertising has evolved into a vital communication system for both consumers and business. Year by year, the cost on advertising is on the increase. For example, in 1980, advertising expenditures in the United States were $\$ 53$ billion; but in 1990, $\$ 130$ billion were spent on advertising; (Belch, 1993). This means the increase in the expenditure of each word of an advertisement, which, in return, calls for concise advertising language. From advertisers' stand, concise language means economy of cost.

On the other hand, conciseness means no less to recipients. An advertisement with more concise language is more effective in arousing the targeted recipients' interest and more effective in persuading them to purchase the advertised products. Generally speaking, a TV commercial lasting even less than thirty seconds and an advertisement put on the street might get only a glimpse from the passers-by. Consequently, concise language is good for the recipients' memory. According to psychological experiments, most people can remember only about four or five out of twenty items that are fresh to them for an instance. Therefore, on the part of readers, conciseness is more effective and more persuasive.

Presuppositions make language concise in that they are ideas taken for granted thus treated as given information and need not to be spoken out. Actually, many of communicators' meanings are encoded at this level. Therefore, we can claim that presupposition makes for economy, without which the interactions would be unexpectedly long-winded.

Presuppositions are pragmatic inferences in another form so that they have the power to make advertising language more concise and more economical. In Peccei's view, presupposition is inferences about what is assumed to be true. (Peccei, 2000) Hence inference means the listener's use of known knowledge to make sense of what is not said or what is not explicit in an utterance. The inference feature of presupposition contributes to the conciseness of advertising language in that it needs not to be outspoken. For further explanation, refer to the following example:

[6] Kodak is Olympic color.

The inferred presupposition that Olympic color has five colors: red, yellow, blue, white and black is omitted. Otherwise, it would be very redundant so as to influence the efficacy of advertising effects. It is not difficult to see the role of presupposition in economizing the language of advertisements and why they are often adopted by the advertisement writers for their actual needs.

\subsubsection{Presupposition and Art of Advertising Language}

Presupposition not only contributes to the conciseness of advertising language, but also promotes its art effect. Lively, vivid and aesthetic advertising language constituents are a main factor for arousing readers' interest. One of Shanghai cosmetic manufacturer -Shanghai Jiahua produces a kind of hair fosterage called Meijiajing, with its advertising slogan "Intelligence does not necessarily mean tiptop (baldness)". "Tiptop intelligence" is a habitual phrase, yet with the negative "not necessarily", it is inevitable that consumers' curiosity will be aroused. After careful consideration, readers finally find out the secret implied and have profound impression on the product. Besides, the sentence 
"Intelligence does not necessarily mean tiptop" also has relaxing and humorous effect with an implication to customers, "our hair fosterage can help an intelligent man to cast off the vexation of baldness".

\section{Explanation of Mental Space Theory for Presupposition Projection in Advertising}

\subsection{Presupposition Projection}

Langendoen \& Savin (1971) held that presuppositions of complex expression are the simple sum of the presuppositions of the parts. But such a simple solution to the presuppositions of complex sentences is far from correct and it has proved in fact extremely difficult to formulate a theory that will predict correctly which presuppositions of component clauses will actually be inherited by the complex whole. This compositional problem is known as the projection problem for presuppositions, which, in a certain angle, refers to the cancellation or defeasibility feature of presupposition we have mentioned previously.

As has been proposed in section 2, projection phenomenon is an important point in presupposition. It is the problem of predicting the presuppositions of complex sentences in a compositional fashion from the presuppositions of their parts. Of course, it is far more complicated to predict when the presuppositions of clauses would fail and when they would survive to become the presuppositions of the whole complex sentence. Projection is one of the most distinctive characteristics of presupposition and also one of the touchstones to test any theory whether it would be successful to handle presuppositions at all. The projection issue is also the focus of the current dissertation.

The projection exhibits two distinctive sides. On the one hand, it is observed that presuppositions of complex sentences survive On the other hand, presuppositions of simple sentences fail when these sentences are embedded in complex ones. Thus, presuppositions can not always be projected from parts to the whole.

An illustration is provided by the following three sentences.

[7a] The king has a son.

[7b] The king's son is bald.

[7c] If the king has a son, the king's son is bald.

Restricting our attention to existence presuppositions resulting from definite descriptions, we observe that [7c] presupposes that there is a king, a presupposition carried by both of its constituent sentences [7a and [7b], but it does not presuppose that the king has a son, a presupposition of its right-hand constituent [7b]. Then what are the general rules that account for this and analogous observations? This we will discuss in detail in Section 4.3.

\subsection{Functions of Mental Space in Advertising}

Mental spaces theory, which the author has discussed in Section 2.2 plays a crucial part in the explanation of several phenomena we encounter, of course, with no exception in advertising. As we have introduced to readers previously the projection problem in presuppositions of advertising mental spaces is exactly the right way to solve this problem which can not be explained without an integration of at least two theories. It is widely observed that in advertising, when an advertiser advertises for a certain product or service, he often transits from one topic to another even in a single but complex advertising sentence whether in Chinese or in English advertising, which is in fact the projection problem we are talking about. Most audience must be confused about the precipitate transition because in their common sense, the advertiser should concentrate on one core, that is, what he is advertising.

Applying the basic statement of mental spaces, we can explain the above confusion from another reasonable and easier angle. The two or more topics can be regarded as two or more mental spaces built by advertisers for audience. It can be explained that the advertiser is focusing on one topic but from different perspectives or mental spaces, which are framed with the unfolding of the presentation of what is advertised. As a matter of fact, the presentation of two or more mental spaces is just used to give more attention to what is being advertised. And in real life, actually we often look at a matter from different perspectives which will give more prominence to that matter. And it is exactly this kind of integration of two or more perspectives into one focal perspective that advertisers apply in the advertising. But how mental spaces are skillfully used for the explanation of projection problem in advertising, the author will go into more details in the following section.

\subsection{Presupposition Projection Principles}

Having illustrated so many cases above of the detailed application of projection rules and strategies in advertisements, we have got the general situations of presupposition projection. There is one important thing that we should bear in our mind: whenever we discuss advertisements, we should never forget that the primary purpose of an advertiser is, with no exception to get their products or services known to the audience. Remembering this, we can 
say that if an advertiser tries to promote from a positive angle, that is, to advertise about the advantages of a product or a service, then usually the presupposed structure is inherited from a daughter space to a parent space (in most cases, referring to the real world space); and if an advertiser advertises from a negative angle, then will come out the converse result, namely, the presupposition will be cancelled in its transition from lower to higher structures.

The unified semantic property of presuppositions as presented above would be like this: they are able to be inherited from space to space under optimization strategies. All the above mentioned presents a general account of how this inheritance takes place. One part of the strategy amounts to: implicit presuppositions are projected until, or unless they are blocked by incompatibility in a higher space (SP2 followed by SPi). From a certain angle, this view is close to the principle of Gazdar's (1979) cancellation theory, which is stipulated as: the "potential"presuppositions are cancelled by stronger implicatures or entailments. Therefore, it is necessary for us to come to the general projection principles.

Fauconnier (1997: 61) has put forward the generally recognized principle for presupposition projection from complements to complex sentences. It is generalized as follows:

A presupposed structure $\mathrm{P}$ in mental space $\mathrm{M}$ will propagate to the next higher space $\mathrm{N}$, unless the structure already in $\mathrm{M}$ or $\mathrm{N}$ is incompatible with $\mathrm{P}$.

We can put it in another informal way, that is, a presupposition floats up until it meets its opposite. To say that a structure of "propagates" from Space $M$ to another space $N$ is actually to say that, if it satisfies elements $m, n, \ldots$ in $M$, it also satisfies their counterparts m',n'...in N, via some connectors.

\section{Conclusion}

In this paper, the author first made a brief review of the theoretical background of what would be referred to for the practical parts of the paper: presupposition and mental spaces.

The functions of presupposition for advertisements can be used as a strategy to accomplish the ultimate purpose of advertising. In other words, they are able to enhance and improve the persuasiveness and attractiveness of the advertising. It also plays a crucial part in balancing the information structure of the advertising texts. As we all know, messages or information that an advertisement aims to transmit has their focus. Or in other words, information transmitted in an advertisement does not have the equal status. Practically, new information tends to be given more prominence and concentration than information which has been given before. And presupposition is an effective and efficient way to emphasize primary information through presupposing insignificant information and messages.

Although Karttunen and Peters (1979) formulated and stipulated the compositional approach to the projection problem, they still failed to explain the counter-examples in a reasonable way. While Gazdar's cancellation approach (1979) seemed to be much more persuasive and powerful than the compositional approach and, in most cases, can solve K \& P's counter-exmpales more effectively, there still remain counter-examples of its own unanswered. What's worse, both of these two approaches are at most descriptively feasible in some aspects, but neither of them is explanatory. Fauconnier's greatest contribution to the explanation of the projection problem lies in the fact that his approach is more explanatory and the pragmatic factors determine the inheritance or blockage of presuppositions from complements of an embedded part into higher complex sentences.

Generally speaking, mental space theory proposed by Fauconnier can be applied in many fields and disciplines. It is a new discipline for the application of mental spaces in presupposition, advanced from different perspectives. This approach has proved to be more promsing in advertising a variety of issues that are more significant in discussing its nature and role in communication. The projection problem in presupposition has long been a touchstone for any theory applied to presupposition. For this, Fauconnier put forward a set of projection rules and strategies as well as corollaries. He tries to tap the projection problem from an angle different from any of other previous theories for presupposition. According to him, the question of whether presuppositions of embedded parts can be inherited, cancelled or suspended in the presence of the whole complex sentence (including compound sentences), can be seen as the question of whether a presupposition which is satisfied or holds in the daughter space $\mathrm{M}$ (part of a complex sentence) can be satisfied in the parent space $\mathrm{R}$ (the whole complex sentence).

\subsection{Limitations}

This study has investigated the cognitive devices used by advertisers to realize their goal of persuasion. The author has tried all that can be attempted to present clear-cut picture to readers. Yet owing to limited objective conditions and the author's own limited academic capacity and resources, this paper may suffer from several limitations.

Firstly, samples used in this paper were only chosen from a restricted number of magazines, newspapers and books. 
Given more time and convenient access to more primary sources, more data and samples on presupposition might be discovered. Secondly, because the author's major concentration is on the language of printed advertising, the visual effects of printed advertisement, which may also contribute a great deal to the persuasive power of advertising, are not explored. However, as a matter of fact, quite a lot of printed advertisements are combinations of languages and pictures. In some cases, pictures can provide certain related contexts and more powerful impact for readers to understand presuppositions in advertising language. A combination of graphic and linguistic devices can better explore the positive roles played by presupposition in helping advertising achieve its persuasive goal. So it deserves further study. Finally, this paper does not provide a large number of samples ranging from commercial, recreational, industrial to other types of advertisements and a good command of certain statistics should have been used as more convincing software. So the results of this paper still leave much room for further implement and research.

\subsection{Recommendations for Further Research}

As the noted Roman playwright Terence pointed out two thousand years ago, "As many men, so many minds; every one has his own way." It is a pity that this paper has only explored what the author can for presupposition projection in advertising. Advertisers in themselves are individuals too. Therefore, it is inevitable that the variety of reasons for their using presupposition projection is infinite. This deserves further study. In the end, hopefully, a quantitative analysis of the occurrence frequencies of different types of presuppositions in printed advertising language can be carried out in the future to contribute further to this study.

\section{References}

Arens, W. F., \& Bovee, C. L. (1994). Contemporary Advertising. BurrRidge, IL: Irwin.

Austin, J. L. (2002). How to Do Things with Words. Beijing: Foreign Language Teaching and Research Press, pp. 205-262.

Beaver, D. I. (2001). Presupposition and Assertion in Dynamic Semantics. New York: CSLI Publications, pp. 49-54.

Belch, G. E., \& Michael, A. B. (1993). Advertising and Promotion-An Integrated Marketing Communication Perspective. USA: Richard D. Irwin, INC.

Brown, G. (1983). Discourse Analysis. Cambridge: Cambridge University Press, pp. 26-34. https://doi.org/10.1017/CBO9780511805226

Crystal, D., \& Davy, D. (1983). The Cambridge Encyclopaedia of Language. Cambridge: Cambridge University Press.

Dinsmore, J. (1981). The Inheritance of Presupposition. Amsterdam: John Benjamin's B.V, pp. 102-110. https://doi.org/10.1075/pb.ii.1

Dryer, M. S. (1996). Focus, Pragmatic Presupposition and Activated Propositions. Journal of Pragmatics. https://doi.org/10.1016/0378-2166(95)00059-3

Emiel, K. (1998). Presupposition and Anaphora. New York: CSLI Publications, pp. 112-120.

Fasold, R. (2000). The Socialinguistics of Language. Beijing: Foreign Language Teaching and Research Press.

Fauconnier, G. (1979). Pragmatics: Implicature, Presupposition and Logical Form. New York: Academic Press.

Fauconnier, G. (1985). Mental Spaces: Aspects of Meaning Construction in Natural Language. Cambridge, MA: The MIT Press.

Fauconnier, G. (1994). Mental Spaces: Aspects of meaning construction in natural Language. Cambridge University Press. https://doi.org/10.1017/CBO9780511624582

Fauconnier, G. (1997). Mappings in Thought and Language. Cambridge: Cambridge University Press. https://doi.org/10.1017/CBO9781139174220

Gazdar, G. (1979a). Pragmatics: Implicature, Presupposition and Logical Form. New York: Academic Press.

Gazdar, G. (1979b). A Solution to the Projection Problem. Oh Dinnee.

George, Y. (2000). Pragmatics. Shanghai: Shanghai Foreign Language Education Press, pp. 30-32.

Goddard, A. (1998). The Language of Advertising. London and New York: Routledge.

Grice, H. (1981). Presupposition and Conversational Implicature. New York: Academic Press, pp. 84-102.

Jackendoff, R. (1983). Semantics and Cognition. Cambridge: Mass. MIT Press, pp. 88-97. 
Karttunen, L. (1973). Presuppositions of compound sentences. Linguistic Inquiry, 4, 169-193.

Karttunen, L. (1979). Presupposition and Linguistic Context. Theoretical Linguistics, 1, 181-194.

Kempson, R. M. (1975). Presupposition and the Delimitation of Semantics. Cambridge: Cambridge University Press, pp. 120-128.

Lakoff, G., \& Johnson, M. (1980). Metaphors We Live By. Chicago and London: The University of Chicago Press.

Langacker, R. W. (1999). Grammar and Conceptualization. Berlin/New York: Mouton de Gruyter. https://doi.org/10.1515/9783110800524

Langendoen, D. T., \& Savin, H. (1971). The projection problem for presuppositions. Studies in Linguistic Semantics. New York: Holt, pp. 91-105.

Levinson, S. C. (1983). Pragmatics. Cambridge: CUP., pp. 77-86. https://doi.org/10.1017/CBO9780511813313

Levinson, S. (2001). Pragmatics. Peking: Foreign Language Teaching and Research Press \& Cambridge University Press.

Marmaridou, S. A. (2000). Pragmatic Meaning and Cognition. John Benjamin's Publishing Co, pp. 120-174. https://doi.org/10.1075/pbns.72

Nunberg. G. (1978). The Pragmatics of Reference. Bloomington. Ind.: Indiana University Linguistics Chub, pp. 57-76.

Packard, V. (1981). The Hidden Persuaders. Harmondsworth: Penguin, pp. 44-62.

Peccei, J. S. (2000). Pragmatics. London and New York: Routledge, pp. 127-140.

Percy, L. (1983). Advertising and Consumer Psychology. New York: Heath and Company, pp. 92-105.

Soames. (1982). How Presuppositions are inherited: a solution to the projection problem. Linguistic Inquiry, 13, 483-545.

Sperber, D., \& Wilson, D. (1985). Relevance: Communication and Cognition. Padstow: Blackwell Publishers Ltd., pp. 64-72.

Stalnaker, R. C. (1970). Presuppositions. Journal of Philosophical Logic, 2, 447-457.

Ungerer, F., \& Schmid, H. J. (2001). An Introduction to Cognitive Linguistics. Beijing: Foreign Language Teaching and Research Press, pp. 147-165.

Van der Sant, A. (1998). Context and Presupposition. London: Croom Helm, pp. 131-145.

Van Fraassen, B. C. (1968). Presupposition, Implication and Self Reference. Journal of Philosophy, 65, 136-152. https://doi.org/10.2307/2024557

\section{Copyrights}

Copyright for this article is retained by the author(s), with first publication rights granted to the journal.

This is an open-access article distributed under the terms and conditions of the Creative Commons Attribution license (http://creativecommons.org/licenses/by/4.0/). 